\title{
Incidental diagnosis of haemophilia: a report of three cases following voluntary medical male circumcision in South Africa
}

Donna Jacobs ${ }^{1}$, Carla Visser ${ }^{2}$, Freck Dikgale ${ }^{1}$, Ngoanamathiba Molepo $^{3}$, Raymond Mabuse ${ }^{1}$, and James Ndirangu ${ }^{4}$

${ }^{1}$ University Research Co LLC

${ }^{2}$ RTI International

${ }^{3}$ Department of Health

${ }^{4}$ University of the Free State Faculty of Health Sciences

May 18, 2020

\begin{abstract}
Medical male circumcisions have been scaled-up for HIV prevention. Three 16-year-old clients were diagnosed with Haemophilia post-VMMC services. Greater emphasis on advocacy, training and placement of qualified health care workers for peri-operative screening and a high index of suspicion for pre-operative diagnosis and appropriate referral for bleeding disorders is essential.
\end{abstract}

\section{Hosted file}

Hemophilia_VMMC_manuscript_revised.docx available at https://authorea.com/users/323443/ articles/452143-incidental-diagnosis-of-haemophilia-a-report-of-three-cases-followingvoluntary-medical-male-circumcision-in-south-africa

\section{Hosted file}

Tables 1-3.docx available at https://authorea.com/users/323443/articles/452143-incidentaldiagnosis-of-haemophilia-a-report-of-three-cases-following-voluntary-medical-malecircumcision-in-south-africa 
Figure 1: Number of VMMCs reported (May 2017-September 2018)

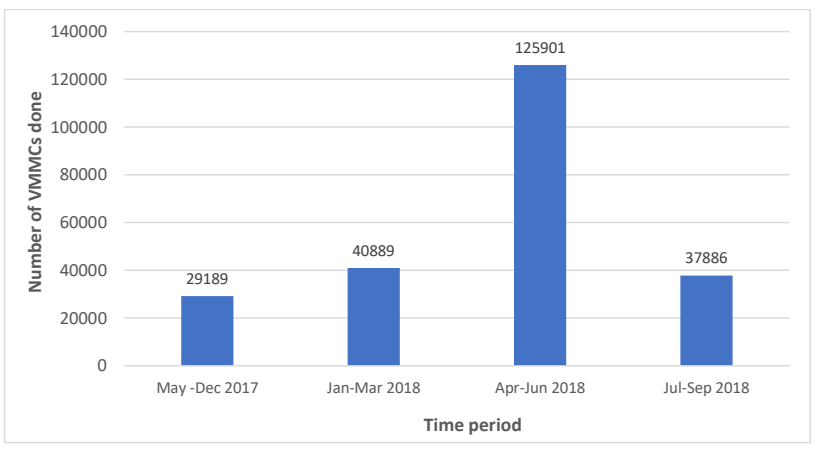


Figure 2: Management of intra-operative and immediate post-operative bleeding

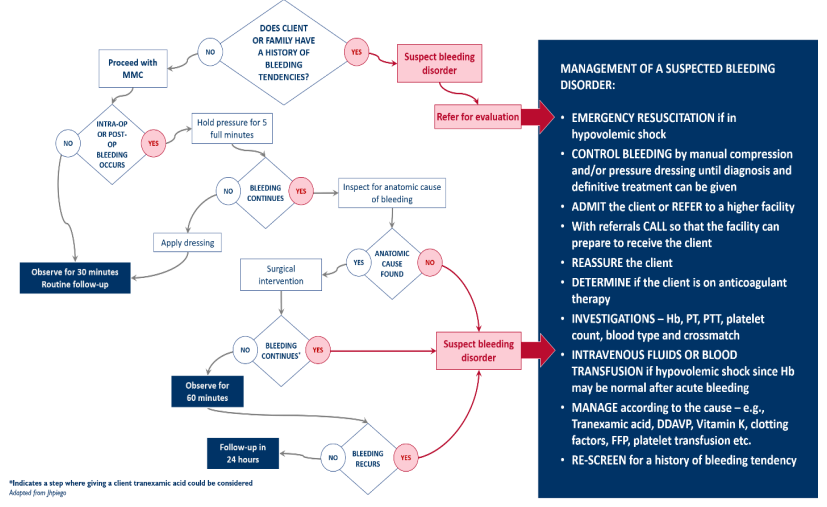

